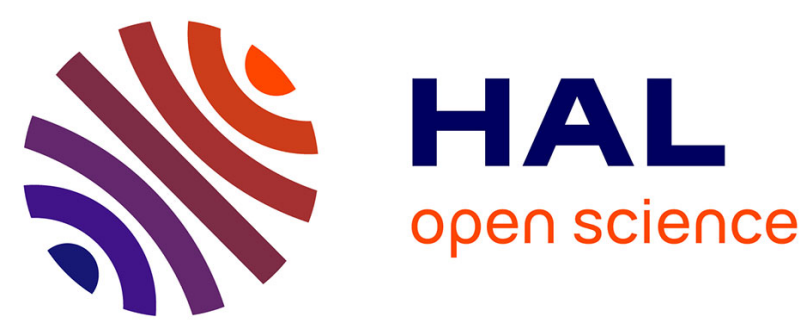

\title{
CATHODOLUMINESCENCE AND ELECTRON BEAM INDUCED CURRENT STUDY OF HYDROGEN TREATMENT OF p-n GaAs JUNCTION
}

D. Araújo, L. Pavesi, Nguyen Ky, J. Ganière, F.K . Reinhart

\section{- To cite this version:}

D. Araújo, L. Pavesi, Nguyen Ky, J. Ganière, F.K . Reinhart. CATHODOLUMINESCENCE AND ELECTRON BEAM INDUCED CURRENT STUDY OF HYDROGEN TREATMENT OF p-n GaAs JUNCTION. Journal de Physique IV Proceedings, 1991, 01 (C6), pp.C6-225-C6-230. 10.1051/jp4:1991635 . jpa-00250721

HAL Id: jpa-00250721

https://hal.science/jpa-00250721

Submitted on 1 Jan 1991

HAL is a multi-disciplinary open access archive for the deposit and dissemination of scientific research documents, whether they are published or not. The documents may come from teaching and research institutions in France or abroad, or from public or private research centers.
L'archive ouverte pluridisciplinaire HAL, est destinée au dépôt et à la diffusion de documents scientifiques de niveau recherche, publiés ou non, émanant des établissements d'enseignement et de recherche français ou étrangers, des laboratoires publics ou privés. 


\title{
CATHODOLUMINESCENCE AND ELECTRON BEAM INDUCED CURRENT STUDY OF HYDROGEN TREATMENT OF p-n GaAs JUNCTION
}

\author{
D. ARAÚJO, L. PAVESI*, NGUYEN HONG KY, J.D. GANIĖRE and FK. REIN- \\ HART \\ Institute for Micro- and Optoelectronics, Swiss Federal Institute of Technology of Lausanne, \\ CH-1015 Lausanne, Switzerland \\ *Department of Physics, University of Trento, I-38050 Povo, Italy
}

\begin{abstract}
The effects of hydrogen diffusion on p-n GaAs junctions have been studied by electron beam induced current (EBIC) and cathodoluminescence (CL) at room temperature. Hydrogen passivates both the acceptors in the p-side of the junction and the donors in the n-side of the junction. As a consequence the diffusion lengths increase, the surface recombination velocities decrease, and, finally, the $C L$ intensity increases after the hydrogen treatment. The observation of hydrogen effects on both sides of the junction indicates that hydrogen diffuses at least in the neutral charge state. We also observe an electron-beam induced reactivation of the passivated centers after exposition of the sample for some minutes to the electron-beam.
\end{abstract}

\section{1.. Introduction}

The modern technology of semiconductor devices demands different post-growth techniques for changing the optoelectronics properties of grown samples. Among them, the diffusion of hydrogen could be a very important tool for fabrication of devices, because it is a planar process convenient to realize an arbitrary pattern of diffused regions. Hydrogen diffusion passivates shallow impurities as well as deep traps [1]. Consequently it changes the physical properties of the samples. However, only a few papers have been published on the use of hydrogen diffusion to improve device performances [2]. This is attributed to the problem of long term stability of the hydrogen effects, and to the fact that hydrogen not only passivates deep traps but also shallow dopants [3-5].

Photoluminescence (PL) measurements on undoped GaAs showed an enhancement of the luminescence after hydrogen treatment [6]. This motivates the present study of $p-n$ junctions as a first step to exploit the beneficial effect of $\mathrm{H}$ diffusion. In fact $\mathrm{p}$ - $\mathrm{n}$ junctions are the fundamental blocks of devices as solar cell, photodetectors and light emitting diodes which could benefit of the enhancement in the luminescence intensity. To investigate their opto-electronic properties we have used the different immaging modes of the scanning electron microscopy (SEM), such as cathodoluminescence (CL) and electron beam induced current (EBIC).

Hydrogen diffusion in $\mathrm{p}$ and $\mathbf{n}$ doped GaAs was studied by Secondary Ion Mass Spectroscopy (SIMS) a few years ago [7]. Hydrogen is a very highly diffusing element which in a relatively short time can diffuse over several $\mu \mathrm{m}$ ( for example $\approx 35 \mu \mathrm{m}$ for a diffusion at $300^{\circ} \mathrm{C}$ lasting 30 minutes in p-doped sample). A shallow $\mathrm{n}^{+}$layer inhibits the in-diffusion of hydrogen in $\mathrm{p}$-type material whereas a shallow $\mathrm{p}^{+}$ layer has no effect on n-type material. This fact raises the question about the charge state of the hydrogen diffusing specie. Theoretical calculations suggests that in $\mathrm{p}$ - and $\mathrm{n}$-doped GaAs, the stable charge state is 
positively or negatively charged hydrogen, respectively [8]. A.J. Tavendale et al [9] and M.H. Yuan et al [10] demonstrated by Revearse Bias Annealing (RBA) that hydrogen indeed drifts as positive and negative charge species in $\mathrm{p}$-doped and $\mathrm{n}$-doped GaAs, respectively.

\section{2.- Experimental technique}

The $\mathrm{p}-\mathrm{n}$ junctions have been obtained by $\mathrm{Zn}$ diffusion in Si-doped samples (nominal donor concentration $\mathrm{N}_{\mathrm{D}} \approx 2 \times 10^{18} \mathrm{~cm}^{-3}$ ). The Zinc diffusion was carried out in closed tubes, using $\mathrm{ZnAs}$ as diffusion source at a temperature of $575^{\circ} \mathrm{C}$ [11]. Resistivity measurements yields a mean $\mathrm{Zn}$ concentration of $\mathrm{N}_{\mathrm{A}} \approx$ $6 \times 10^{19} \mathrm{~cm}^{-3}$ in the diffused region. The diffusion front position measured by SIMS and secondary electrons (SE) gives a diffusion depth of about $1.6 \mu \mathrm{m}$.

For the diffusion of hydrogen we have used a rf plasma $(13.56 \mathrm{MHz})$ produced in an Alcatel GIR300 reactor. The samples were exposed to the plasma at $300^{\circ} \mathrm{C}$ for 45 minutes, at a pressure of $120 \mathrm{mTorr}$ and a power density of $0.74 \mathrm{Wcm}^{-2}$. The samples were exposed prior to the deposition of the contacts. For the contact deposition we used a low temperature technique to prevent the out-diffusion of $\mathrm{H}$. Cleaved faces of the samples were examined with a Cambridge 360 SEM. The CL luminescence radiation was focused at the entrance slit of a $32 \mathrm{~cm}$ focal length monochromator by an elliptical mirror system. The luminescence was detected with a $\mathrm{Si}$ photodiode, or a cooled $\mathrm{Si}$ avalanche photodetector. The sample holder also permits simultaneous EBIC and CL measurements.

\section{3.- Experimental results}

Capacitance-Voltage (C-V) measurements were performed on all the samples. The data shows a strong increase in the depletion layer and a strong reduction of the dopant density after the $\mathbf{H}$ treatment. S.J. Pearton et al [7] studied by SIMS a sample with a structure very similar to the one used in this work: a thin $\left(0.5 \mu \mathrm{m}\right.$ thick) $\mathrm{p}^{+}$layer with $[\mathrm{Zn}] \approx 10^{19} \mathrm{~cm}^{-3}$ grown on a Si doped GaAs sample ([Si] $\approx 10^{17} \mathrm{~cm}^{-3}$ ). The measured hydrogen concentration passes from $2 \times 10^{19} \mathrm{~cm}^{-3}$ in the $\mathrm{p}^{+}$top layer to $1 \times 10^{18} \mathrm{~cm}^{-3}$ in the adjacent $\mathbf{n}$ type $\mathrm{GaAs}$ material. The same measured $\mathrm{H}$ concentration profile was observed in a sample without the $\mathrm{p}^{+}$surface layer. Hence we can assume that in our samples hydrogen diffuses through the junction and passivates the acceptors in the p-side as well as the donors in the n-side. From the C-V data, we found $\mathrm{N}_{\mathrm{AH}} \approx 1 \times 10^{17} \mathrm{~cm}^{-3}$, the electrically active acceptor concentration decreased by two orders of magnitude, and $\mathrm{N}_{\mathrm{DH}} \approx 1 \times 10^{17} \mathrm{~cm}^{-3}$. Indeed an increase in the series resistance was measured: $15 \Omega$ for the non-hydrogenated sample, named PNO, and $500 \Omega$ for sample PNH (both with a sample surface of $\left.6 \mathrm{~mm}^{2}\right)$. In the $\mathrm{p}$-side of the junction the compensation ratio $\left(\mathrm{N}_{\mathrm{A}}+\mathrm{N}_{\mathrm{D}}\right) / \mathrm{N}_{\mathrm{A}}$ passes from $\approx 1$ in sample PN0 to $>10$ in sample PNH.

By measuring the EBIC current, J, under steady state condition it is possible to correlate the EBIC signal decay with the diffusion length $L$ of the minority carrier [13]. For one dimensional diffusion and for weak injection, we have $J \approx J_{0} \exp \{-|x| / L\}$ where $x$ is the distance from the junction and $J_{0}$ the current at the junction. We have measured $J$ for different acceleration voltages in order to change the excitation depth [12]. All the EBIC profiles have been fitted with an exponential function and the so obtained diffusion lengths are reported in Table $\mathrm{I}$.

Considering the boundary condition at the surface (here is the cleavage surface), it is possible to extract the surface contribution from the total minority carrier lifetime $\tau_{\text {tot: }}$ :

$$
\frac{\mathrm{D}}{\mathrm{L}^{2}}=\frac{1}{\tau_{\mathrm{tot}}}=\frac{1}{\tau}+\frac{2 \mathrm{~S}[110]}{\mathrm{d}}=\frac{1}{\tau_{\mathrm{r}}}+\frac{1}{\tau_{\mathrm{nr}}}+\frac{2 \mathrm{~S}[110]}{\mathrm{d}}
$$

where $D$ is the diffusion constant,$\tau_{\mathrm{r}}$ is the radiative lifetime, $\tau_{\mathrm{nr}}$ is the non radiative bulk lifetime, $\tau^{-1}=$ $\tau_{\mathbf{r}}^{-1}+\tau_{n r^{-1}}$ is the bulk total lifetime, $S_{[110]}$ the surface recombination velocity on the [110] surface and $d$ 
the excitation depth. Using eq. (1), we extract $2 S_{[110]} / D$ and $(\tau D)^{-1}$ from Table $I$.

\begin{tabular}{cc|cc|cc}
\hline \hline Tension & \multicolumn{2}{|c|}{$\begin{array}{c}\text { untreated sample } \\
\text { Excitation depth } \\
\text { maximum } \\
\text { diffusion length } \\
\text { (n side) } \\
{[\mu \mathrm{m}]}\end{array}$} & $\begin{array}{c}\text { PNo } \\
\text { diffusion length } \\
\text { (p side) } \\
{[\mu \mathrm{m}]}\end{array}$ & $\begin{array}{c}\text { hydrogen diffused sample PNH } \\
\text { diffusion length } \\
\text { (n side) } \\
{[\mu \mathrm{m}]}\end{array}$ & $\begin{array}{c}\text { diffusion length } \\
\text { (p side) } \\
{[\mu \mathrm{m}]}\end{array}$ \\
\hline 5 & 0.08 & 0.26 & 0.23 & 0.89 & 0.40 \\
10 & 0.26 & 0.33 & 0.25 & 1.10 & 0.35 \\
15 & 0.5 & 0.48 & 0.38 & 1.00 & 0.45 \\
20 & 0.83 & 0.68 & 0.51 & 1.10 & 0.60 \\
\hline
\end{tabular}

TABLE I: Results from the EBIC measurements for the untreated PN0 and hydrogen diffused PNH samples. The maximum excitation depth from the cleavage surface is deduced by the acceleration voltage using the results of Ref. [16].

The diffusion constant is related to the mobility $\mu$ of the minority carriers by the Einstein relation $\mathrm{D}=$ $\mu \mathrm{kT} / \mathrm{q}$, where $\mathrm{q}$ is the electronic charge and $\mathrm{T}$ the temperature. The mobility of holes in a n-region with a dopant density $\mathrm{N}_{\mathrm{D}}$ is approximated by the mobility of holes as majority carrier in a p-region with a density $\mathrm{N}_{\mathrm{A}} \approx \mathrm{N}_{\mathrm{D}}$. A Similar assuption can be made for electrons in the p-region. Using the data reported in Ref. [13] and the Einstein relation, we deduce the diffusion constant (see Table II) and via the data of Table I, the surface velocity $S_{[110]}$ and the minority carrier lifetime $\tau$. The radiative lifetime for band-toband recombinations is $\tau_{\mathrm{r}}=1 /\left(\mathrm{BN}_{\mathrm{I}}\right)$ where $\mathrm{B}$ is the radiative recombination coefficient $\left(\mathrm{B} \approx 2 \times 10^{-10}\right.$ $\mathrm{cm}^{3} / \mathrm{sec}$ for GaAs [14]) and $N_{I}$ is the dopant concentration (where $I=A$ for the p-side of the junction and $\mathrm{I}=\mathrm{D}$ for the $\mathrm{n}$-side) [15]. Hence from the knowledge of $\tau$ and $\tau_{\mathrm{r}}$, the non radiative lifetime $\tau_{\mathrm{nr}}$ and the internal quantum efficiency $\eta=\tau_{n r} /\left(\tau_{n r}+\tau_{r}\right)$ are obtained (see Table II).

\begin{tabular}{|c|c|c|c|c|}
\hline & \multicolumn{2}{|c|}{ untreated sample PNO } & \multicolumn{2}{|c|}{ hydrogen diffused sample PNH } \\
\hline & n-side & p-side & n-side & p-side \\
\hline dopant density $\left[\mathrm{cm}^{-3}\right]$ & $2 \times 10^{18}$ & $6 \times 10^{19}$ & $1 \times 10^{17}$ & $1 \times 10^{17}$ \\
\hline mobility $\left[\mathrm{cm}^{2} /\right.$ Volt sec] & 120 & 1550 & 250 & 1500 \\
\hline $\mathrm{D}\left[\mathrm{cm}^{2} / \mathrm{sec}\right]$ & 3 & 40 & 6 & 40 \\
\hline $\mathrm{S}[\mathrm{cm} / \mathrm{sec}]$ & $150 \times 10^{6}$ & $2329 \times 10^{6}$ & $104 \times 10^{6}$ & $370 \times 10^{6}$ \\
\hline$\tau[\mathrm{sec}]$ & $1.32 \times 10^{-9}$ & $4.4 \times 10^{-11}$ & $1.6 \times 10^{-9}$ & $5.3 \times 10^{-11}$ \\
\hline$\tau_{\mathrm{r}}[\mathrm{sec}]$ & $4 \times 10^{-9}$ & $8.3 \times 10^{-11}$ & $5 \times 10^{-8}$ & $7 \times 10^{-10}$ \\
\hline$\tau_{\mathrm{nr}}[\mathrm{sec}]$ & $1.97 \times 10^{-9}$ & $9.46 \times 10^{-11}$ & $1.7 \times 10^{-9}$ & $5.8 \times 10^{-11}$ \\
\hline$\eta$ & 0.32 & 0.53 & 0.52 & 0.08 \\
\hline
\end{tabular}

TABLE II: Minority carrier parameters deduced from Table I for the untreated PN0 and hydrogen diffused PNH samples.

A relative error of about $50 \%$ is estimated on the value of $\eta$ quoted, due to the errors on the data reported in Table I and the imprecision on the mobility and on the coefficient $B$. 
We show in Figure 1a, the CL intensity profile of PN0 and PNH recorded with an acceleration voltage of $10 \mathrm{keV}$ (excitation depth $\approx 0.26 \mu \mathrm{m}$ ). The band at the $(\mathrm{b})$ mark is due to the recombination of e-h pairs in the p-side of the junction. As the junction is located $1.6 \mu \mathrm{m}$ below the [001] surface ((c) mark) and as the diffusion length is $L \approx 0.3 \mu \mathrm{m}$, the CL intensity profile is strongly affected by the presence of the junction. A meaningfull discussion of the influence of $H$ on $\eta$ and $S$ is not possible on this side of the junction. However an increase by a factor of $\approx 2$ in the total intensity is visible, in agreement with previous results for undoped GaAs [6].

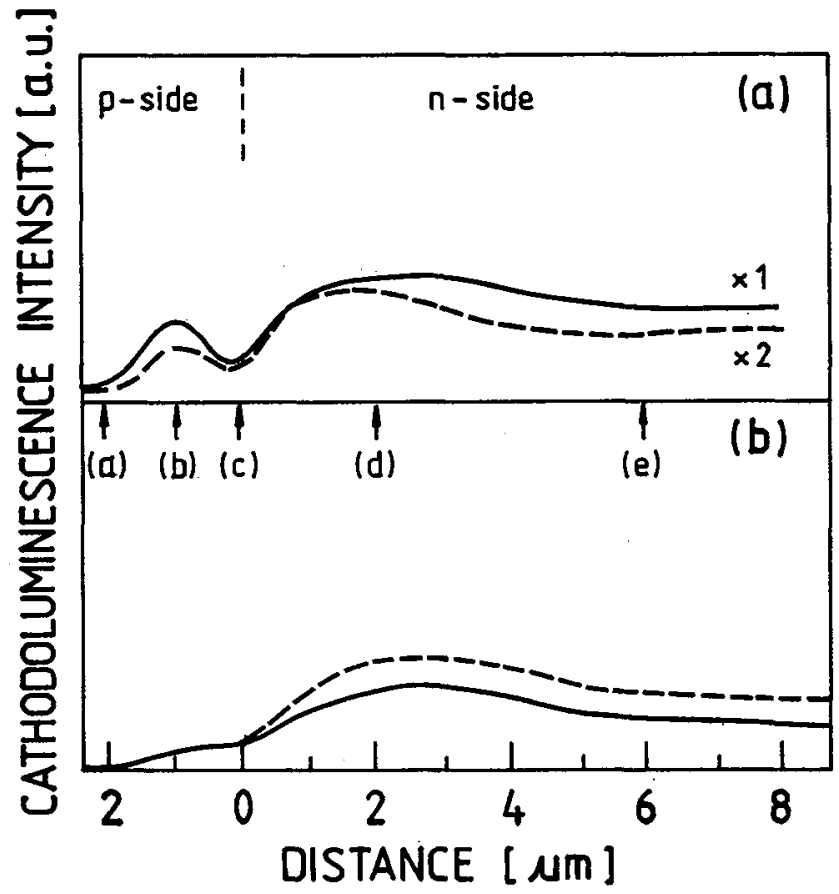

FIGURE 1: Cathodoluminescence (CL) integrated profiles on [110] surface at room temperature. The [001] surface is located at the mark (a). la at beam energy of $\mathrm{V}=10 \mathrm{keV}$ and probe current of $2 \mathrm{nA}$, the full line is the non-hydrogenated PN0 sample and the dashed line the hydrogenated PNH sample. $1 \mathrm{~b}$ at $\mathrm{V}=20 \mathrm{keV}$ and $\mathrm{I}=$ $2 \mathrm{nA}$, the full line after an exposition of $1 \mathrm{~min}$. to the e-beam and the dashed line after an exposition of $13 \mathrm{~min}$.

We observe a strong contribution from the n-side of the junction. The peak at the mark (d), is due to the sum of two contributions. For e-h excitation in the depletion layer, the e-h pair are separated by the electric field present at the junction and no luminescence is visible (this explains the minimum at the junction). As the e-beam goes away from the junction, we have the injections of holes from the p-side. These holes have been generated by reabsorption of the luminescence emitted in the n-side [17]. This effect is relevant as long as we excite at a diffusion length away from the junction. Increasing further the distance, we observe a decrease in the $\mathrm{CL}$ intensity because the contribution from the reabsorption on the p-side decreases. The $\mathrm{CL}$ intensity increases after the $\mathrm{H}$ treatment in agreement with the EBIC findings (Table II). This increase is observed up to $\sim 20 \mu \mathrm{m}$ from the surface. The CL intensity becomes equal to that of sample PNO for depths of $\approx 40 \mu \mathrm{m}$.

An interesting behaviour is observed if we report the CL intensity ratio between the samples PNH and PN0 at the marks (d) and (e) of Fig. 1 versus the acceleration voltage (Table III). The ratios decrease as the penetration depth increases. 
In Figure $1 \mathrm{~b}$, we present the integrated CL profils after exposing the sample PNH for $1 \mathrm{~min}$. and $13 \mathrm{~min}$. to the e-beam (20keV and $1 \mathrm{nA})$. We observe a reduction of the $\mathrm{CL}$ intensity for the longest exposure time.

\begin{tabular}{cc|c|c}
\hline \hline Beam Tension [keV] & $\begin{array}{c}\text { Maximum excitation } \\
\text { depth }[\mu \mathrm{m}]\end{array}$ & $\mathrm{I}_{\mathrm{CL} H} / \mathrm{I}_{\mathrm{CL}}(\mathrm{d})$ & $\mathrm{I}_{\mathrm{CLH}} / \mathrm{I}_{\mathrm{CL}}(\mathrm{e})$ \\
\hline 10 & 0.26 & 2.5 & 2.2 \\
15 & 0.5 & 1.1 & 1.4 \\
20 & 0.83 & 0.3 & 0.4 \\
\hline
\end{tabular}

TABLE III: Integrated $\mathrm{CL}$ intensity ratio $\mathrm{I}_{\mathrm{CLH}} / \mathrm{I}_{\mathrm{CL}}$ between the hydrogenated $\mathrm{PNH}$ sample and the nonhydrogenated PN0 sample. $\mathrm{I}_{\mathrm{CLH}} / \mathrm{I}_{\mathrm{CL}}$ (d) and $\mathrm{I}_{\mathrm{CLH}} / \mathrm{I}_{\mathrm{CL}}$ (e) refer to the $\mathrm{CL}$ intensity recorded at the mark reported in Fig. 1.

\section{4.- Discussion}

The values obtained in Table II show a strong variation of the electronic properties after hydrogen treatement. The surface recombination velocity $S_{[110]}$ decreases by a factor $\approx 1.5(\approx 6)$ in the $n$-side ( $p$ side). The total lifetime increases in the $\mathrm{n}$ and $\mathrm{p}$ region. Consequently, the internal quantum efficiency is affected by the hydrogen diffusion. It augments by a factor $\sim 2$ in the $n$-side and decrease by a factor $\sim 7$ on the $p$-side. The quantum efficiency reduction on the p-side is due to the radiative lifetime increase caused by the reduction of $\mathrm{N}_{\mathrm{A}}[18]$ and to the drop of the non-radiative lifetime.

We interpret the variation of the $\mathrm{CL}$ intensity ratio $\mathrm{I}_{\mathrm{CLH}} / \mathrm{I}_{\mathrm{CL}}$ with beam energy by the differences in the influence of the surface recombination velocity on the radiative recombinations. The [110] surface traps more carriers in PNO than in PNH. Then $\mathrm{I}_{\mathrm{CLH}} / \mathrm{I}_{\mathrm{CL}}$ become higher lowering the beam voltage. The $\mathrm{CL}$ ratio is not dominated only by the surface recombination velocity. Another effect is also present. The augmentation of the diffusion length after hydrogen treatment (see Table I) produces a higher collection of carriers at the junction. This induce a decrease of the CL signal and then it explains the value below 1 of the CL ratio at $20 \mathrm{keV}$. The integrated EBIC signal on the $n$-side of the junction increases indeed by a factor $\approx 2$ after the hydrogen treatment. And this ratio is approximatively constant with the beam energy.

In Figure $1 \mathrm{~b}$, we have shown an increase of the $\mathrm{CL}$ intensity after a relatively long exposure time of the sample PNH to the e-beam. This is due to a e-beam induced reactivation of the impurities. Thus the diffusion length of the carrier decreases and, as argued above, the CL intensity signal increases. The Si$\mathrm{H}$ neutral complex formed during the passivation is dissociated during the minority carrier injection:

$$
(\mathrm{Si}-\mathrm{H})+\mathrm{h} \Rightarrow \mathrm{Si}^{+}+\mathrm{H}^{\mathrm{o}}
$$

A similar phenomenon in p-doped GaAs has been reported in Ref. [9].

\section{5.- Conclusion}

Our observations imply that $\mathrm{H}$ diffuses relatively rapidly in p-type $\mathrm{GaAs}$, and that the electric field due to the $\mathrm{p}-\mathrm{n}$ junction has a minor influence on the motion of the diffusing specie. In fact relevant $\mathbf{H}$ induced variations of the physical properties have been observed on both sides of the junction. This fact suggest that $\mathrm{H}$ diffuses at least in the neutral charge state. $\mathrm{H}$ passivates the impurites accordingly to the following model [1]. As $\mathrm{H}$ enters in the p-side of the junction, it looses one electron which cancells a free hole and then the positively charged $\mathrm{H}$ is attracted by the negatively charged acceptor forming a neutral complex (passivation of dopant). The $\mathrm{H}$ bound in the complex is no longer able to move. The neutral $\mathrm{H}$ diffuses 
and passes the junction. In the $\mathrm{n}$-side, the neutral $\mathrm{H}$ looses a hole which recombines with an electron. Then a complex is formed between the positively charged donor and the negatively charged $\mathrm{H}$. The ebeam induced reactivation confirms this scheme. However, our study does not exclude the possibility that $\mathrm{H}$ diffuses also in other charge states.

\section{Acknowledgements}

This work was made possible through grants from the Swiss National Science Foundation $\left(\mathrm{n}^{\circ} 2.979-\right.$ 0.88). The authors want to thank G.Peter, B.Garoni and I.Magnenat for their useful technical support.

\section{6.- References}

[1] For an up-to-date review on the problem of $\mathrm{H}$ in semiconductors see the volume Physica $\mathrm{B} 170$ (1991)

[2] E. Constant, in ref. [1] pag. 397.

[3] S.J. Pearton, W.C. Dautremont-Smith, J. Chevallier, C.W. Tu and K.D. Cumming, J. Appl. Phys. 59, 2821 (1986)

[4] N.M. Johnson, R.D. Burnham, R.A. Street and R.C. Thornton, Phys. Rev. B 33, 1102 (1986)

[5] J. Chevallier, W.C. Dautremont-Smith, C.W. Tu and S.J. Pearton, Appl. Phys. Lett. 47, 108 (1985)

[6] L. Pavesi, F. Martelli, D. Martin and F.K. Reinhart, Appl. Phys. Lett. 54, 1522 (1989)

[7] S.J. Pearton, W.C. Dautremont-Smith, J. Lopata, C.W. Tu and C.R. Abernathy, Phys. Rev. B 36, 4260 (1987)

[8] L. Pavesi, P. Giannozzi and F.K. Reinhart, Phys. Rev. B 42, 1864 (1990); L. Pavesi, P. Giannozzi in ref [1] pag. 392.

[9] A.J. Tavendale, S.J. Pearton, A.A. Williams and D Alexiev, Appl. Phys. Lett. 56, 1457 (1990)

[10] M.H. Yuan, L.P. Wang, S.X. Jin, J.J. Chen and G.G. Qin, Appl. Phys. Lett. 58, 925 (1991)

[11] N.H. Ky, L. Pavesi, D. Araújo, J.D. Ganière and F.K. Reinhart, J. Appl. Phys. 69, 7585 (1991).

[12] F. Berz and H.K. Kuiken, Solid-State Electronics 19, 437 (1976).

[13] Landolt-Börnstein, Numerical data and functional relationships in Science and Technology: New Series, vol. 17 Semiconductors, subvolume a, ed. in chief K.H. Hellweye, (Springer-Verlag, Berlin Heidelberg, 1987) pag. 218.

[14] C. Casey and F. Stern, J. Appl. Phys. 47, 631 (1976).

[15] S.M. Sze, Physics of Semiconductor Devices (A Wiley-Interscience publication, John Wiley \& Sons, New York, 1981).

[16] J.F. Bresse, Scanning Electron. Microscopy IV, 1487 (1982).

[17] F. Koch and G. Oelgart, phys. stat. sol. 104, 931 (1987)

[18] R.J. Nelson and R.G. Sobers, J. Appl. Phys. 49, 6103 (1978). 